\title{
Argan Oil Exerts an Antiatherogenic Effect by Improving Lipids and Susceptibility of LDL to Oxidation in Type 2 Diabetes Patients
}

\author{
M. M. Ould Mohamedou, ${ }^{1}$ K. Zouirech, ${ }^{1}$ M. El Messal, ${ }^{2}$ M. S. El Kebbaj, ${ }^{1}$ \\ A. Chraibi, ${ }^{3}$ and A. Adlouni ${ }^{1}$ \\ ${ }^{1}$ Lipoproteins and Atherosclerosis Research Laboratory, Faculty of Sciences Ben Msik, Casablanca, Morocco \\ ${ }^{2}$ Laboratory of Biochemistry, Faculty of Sciences Ain Chock, Casablanca, Morocco \\ ${ }^{3}$ Endocrinology and Nutrition, and Metabolic Diseases Department, University Hospital of Ibn Sina, Rabat, Morocco
}

Correspondence should be addressed to A. Adlouni, adlounia@yahoo.fr

Received 1 July 2011; Accepted 22 August 2011

Academic Editor: Jack R. Wall

Copyright ( 2011 M. M. Ould Mohamedou et al. This is an open access article distributed under the Creative Commons Attribution License, which permits unrestricted use, distribution, and reproduction in any medium, provided the original work is properly cited.

\begin{abstract}
In this study, we investigate the effect of argan oil consumption on serum lipids, apolipoproteins (AI and B), CRP, and LDL susceptibility to oxidation in type 2 diabetic patients which are known to have a high level of cardiovascular risk due to lipid abnormalities and lipid peroxidation. For that, 86 type 2 diabetic patients with dyslipidemia were randomized to one group consuming $25 \mathrm{~mL} /$ day of argan oil during 3 weeks and control group consuming $20 \mathrm{~g} /$ day of butter in breakfast. After argan oil intervention, serum triglycerides decreased by $11.84 \%,(P=0.001)$, total chol by $9.13 \%,(P=0.01)$, and LDL-chol by $11.81 \%$, $(P=0.02)$. However, HDL-chol and Apo AI increased $(10.51 \%, P=0.01$ and $9.40 \%, P=0.045$, resp.). Susceptibility of LDL to lipid peroxidation was significantly reduced by increasing of $20.95 \%,(P=0.038)$ in lag phase after argan oil consumption. In conclusion, we show for the first time that consumption of argan oil may have an antiatherogenic effect by improving lipids, and the susceptibility of LDL to oxidation in type 2 diabetes patients with dyslipidemia, and can therefore be recommended in the nutritional management of type 2 diabetes.
\end{abstract}

\section{Introduction}

Increased cardiovascular morbidity and mortality in patients with type 2 diabetes is well established [1]. In Morocco, the diabetes prevalence was $6.6 \%$ in 2000, while in 2003 it was progressed to $10 \%[2]$.

Patients with type 2 diabetes have a high level of cardiovascular risk due to lipid abnormalities and lipid peroxidation which are responsible in the development of atherogenesis. These lipid disorders include not only quantitative but also qualitative abnormalities of lipoproteins. The main quantitative abnormalities are increased triglyceride (TG) levels and decreased HDL-cholesterol (HDL-chol) levels [3, 4]. The main qualitative abnormalities include large very low density lipoprotein (VLDL) particles, relatively rich in triglycerides, small dense low density lipoprotein (LDL) particles, increased triglyceride content of LDL and high density lipoprotein (HDL), glycation of apolipoproteins, and increased susceptibility of LDL to oxidation [5]. The American Diabetes Association (ADA) has set desirable LDL cholesterol (LDL-chol), HDL-chol, and TG levels as $<100,>40$ in men/ $>50$ in women, and $<150 \mathrm{mg} / \mathrm{dL}$, respectively [6]. Apolipoprotein B (Apo B) reflects the total mass of atherogenic particles (VLDL, Intermediate density lipoprotein (IDL), and LDL) and is associated with cardiovascular disease (CVD) independently of LDL-chol levels [7, 8]. In type 2 diabetes patients without other major CVD risk factors, Apo B should be $<90 \mathrm{mg} / \mathrm{dL}$. In case of diabetes associated with one or more other cardiovascular risk factors, Apo B should not exceed $80 \mathrm{mg} / \mathrm{dL}$ [9]. Some authors have suggested that in type 2 diabetics compared to healthy controls, LDL is more susceptible to oxidation, and diabetic patients have higher levels of oxidation which may contribute to the more aggressive atherosclerosis when 
compared to nondiabetics [10]. Apolipoprotein AI (Apo AI) is the major component of HDL constituting $45 \%$ of its molecular mass and is responsible for its antiatherogenic property by acting as a cofactor for the enzyme lecithin cholesterol acyltransferase (LCAT) and as a mediator in transfer of cholesterol from cells to HDL particles, which are key steps involved in reverse cholesterol transport [11]. It is known that in diabetic patients, the plasma concentration of Apo AI is lower compared with healthy subjects [12]. The Apo B/Apo AI ratio may represent the balance between proatherogenic and antiatherogenic lipoproteins [13]. The Apo $\mathrm{B} / \mathrm{Apo} \mathrm{AI}$ ratio has been reported to predict cardiovascular risk better than cholesterol value [14]. The pathophysiology of lipid abnormalities in type 2 diabetes is not yet totally explained. However, insulin resistance and the "relative" insulin deficiency, observed in patients' with type 2 diabetes, are likely playing a crucial role since insulin has an important function in the regulation of lipid metabolism [5]. The Creactive protein $(\mathrm{CRP})$, an inflammatory marker, is known to play a role in the insulin resistance [15]. Indeed, several studies showed that the association of CRP with insulin resistance was independent of obesity [16].

The diet and lifestyle are an integral part of any diabetes management plan [17]. In the traditional Moroccan diet, argan oil (extracted from Argania spinosa, an endemic tree of south-western Morocco) is usually consumed at breakfast, especially in the south-western region of the country. Generally, this oil is rich in unsaturated fatty acids (UFA), principally oleic and linoleic acids (44.8 and 33.7\%, resp.) [18]. Interestingly, the unsaponifiable fraction ( $1 \%$ of the oil constituents) of argan oil is mainly rich in antioxidant compounds such as tocopherols, which are present in a higher proportion compared to olive oil $(637 \mathrm{mg} / \mathrm{kg}$ versus $258 \mathrm{mg} / \mathrm{kg}$, resp.) and especially in its $\gamma$-isoform (75\%) [18]. The quality of fatty acids present in argan oil and their composition in antioxidants give it a special significance in the nutritional prevention of CVD and other diseases [1925]. Consumption of argan oil could contribute to reduce the risk in patients at high cardiovascular risk. The recent data, published by our team, have shown the beneficial effect of argan oil on lipid profile and LDL susceptibility to lipid peroxidation in healthy subjects and dylipidemic patients. That why we were interested to evaluate its effects in type 2 diabetic patients with dyslipidemia.

\section{Patients and Methods}

2.1. Patients. The study protocol was approved by the regional Committee for Ethics. This study was conducted on diabetic patients with dyslipidemia aged $40-80$ years consulting the endocrinology department (Ibn Sina university hospital, Rabat, Morocco). Exclusion criteria include presence of hepatic or renal disease, myocardial infarction, cigarette smoking, use of dietary antioxidant supplements, and treatment with insulin, lipid lowering drugs, or hormone therapy during the preceding 6 months. The protocol and objectives of this study were explained to the participants in detail. Among 127 patients, a total of 86 diabetic patients without any diabetes cardiovascular complications
TABLe 1: Chemical composition of argan oil [22].

\begin{tabular}{lc}
\hline Fatty acids & $\%$ \\
\hline C $16: 0$ & 13.4 \\
C $18: 0$ & 5.1 \\
C $18: 1$ & 44.8 \\
C $18: 2$ & 35.7 \\
C $18: 3$ & 0.1 \\
\hline Sterols & $\mathrm{mg} / 100 \mathrm{~g}$ oil \\
\hline Schottenol & 142 \\
Spinasterol & 115 \\
Stigmasta-8,22-dien-3 $\beta$-ol & 9 \\
Other & 29 \\
\hline Tocopherols & $\mathrm{mg} / \mathrm{Kg}$ oil \\
\hline$\alpha$ & 35 \\
$\beta$ & 122 \\
$\gamma$ & 480 \\
\hline Phenolics compound & $\mu \mathrm{g} / \mathrm{Kg}$ oil \\
\hline Vanilic acid & 67 \\
Syringic acid & 37 \\
Ferulic acid & 3147 \\
Tyrosol & 12 \\
\hline
\end{tabular}

(retinopathy, nephropathy, and myocardial infarction) completed the study and 41 dropped out because of personal reasons. During this study, the daily habits of the participants such as physical activities, number of sleeping hours, and working time were not changed. All patients were informed verbally and in writing, and all patients signed an informed consent form before entering the study.

2.2. Design. Study design (Figure 1) was two diet periods. In the first diet period for 2 weeks (baseline diet), all the patients consumed $20 \mathrm{~g} /$ day of butter with toasted bread for breakfast. In the second diet period for 3 weeks, the patients were randomized to two diet groups: one group of 43 patients consuming $25 \mathrm{~mL} /$ day of argan oil (argan oil group) at breakfast, and the second group of 43 patients consuming $25 \mathrm{~g} /$ day of butter (control group).

2.3. Biological Materials. The argan oil supplied and distributed to the participants was purchased from the same origin and was extracted by industrial process [26]. Its fatty acid and minor components composition is presented in Table 1 [22].

2.4. Blood Collection. At the end of each diet period, venous blood was collected into draw tubes after $12 \mathrm{~h}$ fast. Plasma was obtained by centrifugation for $12 \mathrm{~min}$ for $4000 \mathrm{rpm}$. Plasma samples were stored at $-20^{\circ} \mathrm{C}$ until analysis.

2.5. Food Questionnaire. All of patients have been investigated in relation to their daily eating habits through a comprehensive food questionnaire covering all foods commonly consumed in Morocco and covers all meals and snacks daily. 


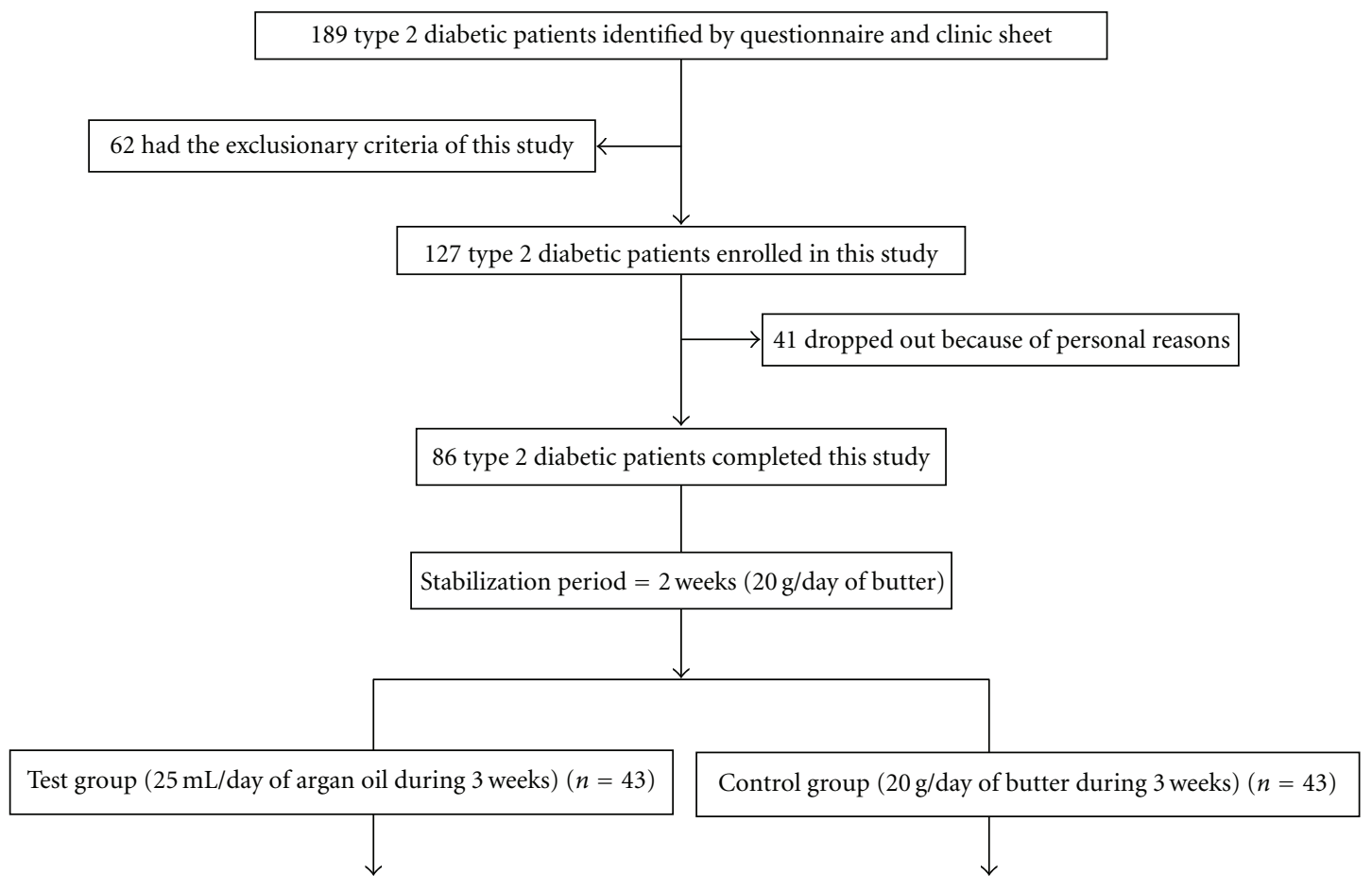

FIGURE 1: Design of study.

2.6. Measurements. Demographic and anthropometric parameters (age, sex, weight, body mass index (BMI), waist circumference) were evaluated in the patients at baseline. Serum total-chol (TC) and HDL-chol levels were determined by enzymatic colorimetric procedure of Richmond [27] (Randox cholesterol enzymatic kit for cholesterol, and Randox HDL cholesterol precipitant for HDL-C; Crumlin Co., Antrim, UK) adapted for a spectrophotometer (Helios). Serum triglycerides were quantified by an enzymatic colorimetric procedure of Trinder [28]. (Randox, triglycerides enzymatic kit, Crumlin Co, Antrim United Kingdom). In contrast, LDL-chol was obtained by the Friedewald formula [29], that is, LDL-chol = total cholesterol - (triglycerides/5) - HDL-chol. Plasma Apo A1 and Apo B were measured by immunoturbidimetry [30-33] (Cobas Integra 700) with a both inter-assay and intra-assay coefficient of variation of $2 \%$ and $1.5 \%$ for Apo AI, and $2.1 \%$ and $0.66 \%$ for Apo B, respectively. The sensitivity is $0.19 \mathrm{mg} / \mathrm{dL}$ for Apo AI and $0.052 \mathrm{mg} / \mathrm{dL}$ for Apo B. The HbAlc was measured using a commercial kit (Glycotest 2; Pierce, Rockford, IL). Serum CRP concentration was measured by immunoturbidimetry with latex particles sensitized with specific antibodies [34-36] (Cobas Integra 700 , Roche) with a both inter-assay and intra-assay coefficient of variation of $2.9 \%$ and $1.8 \%$, and sensitivity of $0.085 \mathrm{mg} / \mathrm{dL}$. The creatinine was measured by Jaffe kinetic reaction buffer without deproteinization [37-39] with a both inter-assay and intra-assay coefficient of variation of $3.8 \%$ and $0.8 \%$, and sensitivity of $0.017 \mathrm{mg} / \mathrm{dL}$. From the plasma, LDL fraction from each sample was isolated by sequential preparative ultracentrifugation using a Beckman ultracentrifuge as described by Sattler et al. [40]. After centrifugation at $100000 \mathrm{rpm}$ during $2 \mathrm{~h}$ at $15^{\circ} \mathrm{C}$ in a Beckman TLA 100.4 rotor, the LDL fractions were collected with a syringe, and protein composition was measured by commercial assay (Pierce method, Rockford, IL, USA) using bovine serum albumin as a standard. Conjugated diene formation was determined spectrophotometrically by the measure of the absorbance at $234 \mathrm{~nm}$ (U-3000 spectrophotometer, Hitachi). Plasma was diluted (1/100) with phosphate buffer before each measure. LDL at concentration of $100 \mathrm{mg} / \mathrm{mL}$ underwent in vitro oxidation induced by incubation with $10 \mathrm{Mm}$ $\mathrm{CuSO} 4$ at $37^{\circ} \mathrm{C}$. The kinetics of conjugated dienes formation was continuously monitored by measuring the absorbance at $234 \mathrm{~nm}$, every $10 \mathrm{~min}$ for at least $8 \mathrm{~h}$. The lag phase (LP) of conjugated dienes formation, maximal rate of dienes production (MR), and maximum dienes production was determined according to the method of Kleinveld [41].

2.7. Statistical Analysis. Statistical analysis was done using SPSS 17.0 software and using the student test for comparison of two means. The results are expressed as mean \pm standard deviation. Difference in LDL susceptibility to lipid peroxidation was analyzed by the Wilcoxon signed rank test. Differences are considered significant when the $P$ value is $<0.05$.

\section{Results}

The baseline characteristics of the patients, including sex and age as well as the risk factors associated with atherosclerosis diseases, are detailed in Table 2. Average glycemic control was poor $(>7 \%)$. Indeed, the mean of $\mathrm{HbAlc}$ in both argan oil and control group was $8.8 \%$ and $9 \%$, respectively. 
TABLE 2: Baseline anthropometrical and biological characteristics of both study groups.

\begin{tabular}{|c|c|c|}
\hline Characteristics & Argan oil group & Control group \\
\hline $\mathrm{M} / \mathrm{W}$ & $23 / 20$ & $22 / 21$ \\
\hline Age (years) & $52.09 \pm 10.75$ & $52.29 \pm 10.51$ \\
\hline Diabetes (years) & $7.63 \pm 4.34$ & $7.71 \pm 4.8$ \\
\hline Family history (\%) & 19.56 & 15.38 \\
\hline SBP (mmHg) & $12.00 \pm 2.42$ & $12.77 \pm 2.43$ \\
\hline $\mathrm{DBP}(\mathrm{mmHg})$ & $7.67 \pm 1.28$ & $7.74 \pm 1.34$ \\
\hline Hypertension (\%) & 26.08 & 23.03 \\
\hline Weight (kg) & $75.61 \pm 13.08$ & $76.03 \pm 13.25$ \\
\hline BMI $\left(\mathrm{kg} / \mathrm{m}^{2}\right)$ & $29.67 \pm 5.00$ & $29.71 \pm 4.90$ \\
\hline Overweight (\%) & 26.08 & 25.64 \\
\hline Obesity (\%) & 19.57 & 21.76 \\
\hline Waist circumference $(\mathrm{cm})$ & $100.79 \pm 15.46$ & $102 \pm 14.92$ \\
\hline $\begin{array}{l}\text { Metabolic syndrome } \\
\text { according to IDF definition \% }\end{array}$ & 49.34 & 51.84 \\
\hline $\mathrm{TC}(\mathrm{mg} / \mathrm{dL})$ & $197 \pm 35$ & $191 \pm 37$ \\
\hline TG $(\mathrm{mg} / \mathrm{dL})$ & $152 \pm 55$ & $150 \pm 56$ \\
\hline HDL-chol (mg/dL) & $39 \pm 7$ & $34 \pm 5$ \\
\hline LDL-chol (mg/dL) & $127 \pm 39$ & $127 \pm 33$ \\
\hline Apo B (mg/dL) & $82.90 \pm 20.13$ & 86.83 \\
\hline Apo AI (mg/dL) & $106.84 \pm 17$ & $106.24 \pm 14$ \\
\hline Apo B/Apo AI & 0.65 & 0.66 \\
\hline $\mathrm{HbA1C} \%$ & $8.8 \pm 1$ & $9 \pm 0.7$ \\
\hline CRP (mg/dL) & $5.22 \pm 1.7$ & 5.341 .4 \\
\hline Creatinine (mg/dL) & $6.1 \pm 1.16$ & $6.07 \pm 1.2$ \\
\hline Lag time (min) & 52.70 & 53 \\
\hline $\begin{array}{l}\mathrm{MR} \text { (mol diene/mol } \\
\mathrm{LDL} / \mathrm{min})\end{array}$ & 3.83 & 3.86 \\
\hline MDP (mol diene/mol LDL) & 520.17 & 521.80 \\
\hline
\end{tabular}

Abbreviations: Apo AI: apolipoprotein AI; Apo B: apolipoprotein B; BMI: body mass index; CRP: C-reactive protein; DBP: diastolic blood pressure; HDL-chol: high density lipoprotein cholesterol; IDF: International Diabetes Federation; LDL-chol: low density lipoprotein cholesterol; M: men; MDP: maximum diene production; MR: maximal rate; TC: total cholesterol; TG: triglycerides; W: women.

According to the International Diabetes Federation definition (IDF) [42], the metabolic syndrome (MS) percentage in both groups of argan oil and control was $49.34 \%$ and $51.15 \%$, respectively. The most frequent components of the metabolic syndrome in our diabetic patients in addition to hyperglycemia were central obesity and high level of plasma triglycerides. Total of the patients had at least two MS components. In argan oil group, $40 \%$ of patients had tree of the five IDF criteria, $50 \%$ had four, and $10 \%$ had the five MS components. In control group, $30 \%$ of patients had tree of the five IDF criteria, $66 \%$ had four, and $4 \%$ had the five MS components. The Apo B/Apo AI ratio is strongly associated with the presence of individual metabolic syndrome components, with the metabolic syndrome itself, and with insulin resistance. The Apo B/Apo AI ratio was elevated in both argan oil and control group at baseline $(0.65$ and 0.66 , resp.).

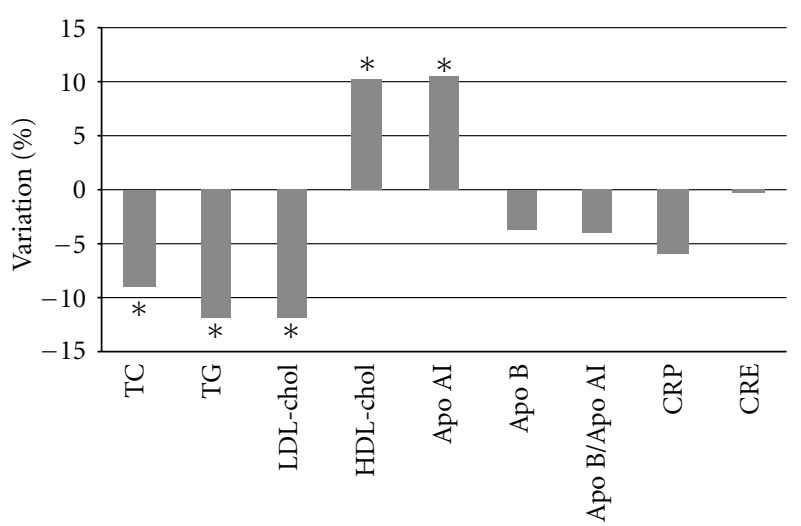

Figure 2: Variations of different parameters in argan oil groups after three weeks of interventions. Abbreviations: Apo AI: apolipoprotein AI; Apo B: apolipoprotein B; CRE: creatinine; CRP: C-reactive protein; HDL-Chol: high density lipoprotein cholesterol; LDL-chol: low density lipoprotein cholesterol; TC: total cholesterol; TG: triglycerides; * significantly different.

The analysis of diet questionnaire showed that $92 \%$ of patients consume at least once a day fruits and vegetables, $55 \%$ consume at least once a day cereals and legumes. However, only $50 \%$ consume meat, tea, and coffee at least once a week, whereas no tendency to consume oils, fats, and sugar was noted.

The results obtained after three weeks of intervention with argan oil showed a significant change in lipid parameter and apolipoprotein AI (Table 3). The change in CRP and Apolipoprotein B was not significant but was a tendency of reduction (a decrease of $5.85 \%$ and $3.65 \%$, resp.) (Figure 2). Serum triglycerides decreased by $11.84 \%,(P=0.001)$, total cholesterol by $9.13 \%,(P=0.01)$, and LDL-chol by $11.81 \%$ $(P=0.02)$. However, a significant increase was observed in HDL-chol and Apo AI plasma concentration $(10.51 \%, P=$ 0.01 and $9.40 \% P=0.045$, resp.). Susceptibility of LDL to lipid peroxidation was significantly decreased by increasing of the lag phase $(20.95 \%, P=0.027)$ after 3 weeks of argan oil intervention. The MR and MDP were significantly decreased (Table 4).

\section{Discussion}

The quality of fatty acids contained in argan oil and the abundance of antioxidant compounds in the unsaponiable fraction suggests a putative use for this oil in nutritional prevention against some pathologies such as cardiovascular diseases (CVD). However, only few studies have reported beneficial pharmacological effects of argan oil and its compounds in blood pressure, lipids and lipids peroxidation in human and animal models [19-23]. This is probably related to its fat composition, $45 \%$ monounsaturated fatty acids (MUFA) and 35\% polyunsaturated fatty acids (PUFA), and to its minor compounds such as polyphenols, phytosterols, and tocopherols [18]. The hypolipidemic and the antioxidant effects of argan oil were demonstrated in healthy subject 
TABLE 3: Variations of different parameters in both groups after three weeks of intervention.

\begin{tabular}{|c|c|c|c|c|c|c|c|c|c|c|}
\hline \multirow{2}{*}{\multicolumn{2}{|c|}{ Groups }} & \multicolumn{9}{|c|}{ Parameters } \\
\hline & & $\begin{array}{c}\mathrm{TC} \\
(\mathrm{mg} / \mathrm{dL})\end{array}$ & $\begin{array}{c}\mathrm{TG} \\
(\mathrm{mg} / \mathrm{dL})\end{array}$ & $\begin{array}{l}\text { LDL-chol } \\
\text { (mg/dL) }\end{array}$ & $\begin{array}{l}\text { HDL-chol } \\
(\mathrm{mg} / \mathrm{dL})\end{array}$ & $\begin{array}{l}\text { Apo AI } \\
(\mathrm{mg} / \mathrm{dL})\end{array}$ & $\begin{array}{c}\text { Apo B } \\
(\mathrm{mg} / \mathrm{dL})\end{array}$ & $\begin{array}{c}\text { ApoB/Apo } \\
\text { AI }\end{array}$ & $\begin{array}{c}\text { CRP } \\
(\mathrm{mg} / \mathrm{dL})\end{array}$ & $\begin{array}{c}\text { CRE } \\
(\mathrm{mg} / \mathrm{dL})\end{array}$ \\
\hline \multirow{3}{*}{$\begin{array}{l}\bar{O} \\
\stackrel{\Xi}{0} \\
\stackrel{0}{0}\end{array}$} & $\begin{array}{l}\text { After stabilization } \\
\text { ( } 2 \text { weeks })\end{array}$ & $191 \pm 37$ & $150 \pm 56$ & $127 \pm 33$ & $34 \pm 5$ & $106.24 \pm 14$ & $86.83 \pm 20.63$ & $0.66 \pm 0.10$ & $3.96 \pm 1.4$ & $6.07 \pm 1.2$ \\
\hline & $\begin{array}{l}\text { After intervention } \\
\quad \text { (3 weeks) }\end{array}$ & $192 \pm 35$ & $148 \pm 54$ & $127 \pm 34$ & $35 \pm 5$ & $105.71 \pm 17$ & $88.11 \pm 13.02$ & $0.67 \pm 0.17$ & $4.0 \pm 1.5$ & $6.21 \pm 1.4$ \\
\hline & $P$ & 0.331 & 0.367 & 0.451 & 0.329 & 0.358 & 0.462 & 0.405 & 0.427 & 0.391 \\
\hline \multirow{3}{*}{$\begin{array}{l}=\overline{0} \\
\overline{7} \\
\text { क्ष } \\
\dot{z}\end{array}$} & $\begin{array}{l}\text { After stabilization } \\
\text { ( } 2 \text { weeks })\end{array}$ & $197 \pm 35$ & $152 \pm 55$ & $127 \pm 39$ & $39 \pm 7$ & $106.84 \pm 17$ & $82.90 \pm 20.13$ & $0.65 \pm 0.13$ & $4.27 \pm 1.7$ & $4.65 \pm 1.16$ \\
\hline & $\begin{array}{l}\text { After intervention } \\
\qquad(3 \text { weeks })\end{array}$ & $179 \pm 36$ & $134 \pm 43$ & $112 \pm 33$ & $43 \pm 10$ & $117.52 \pm 10$ & $79.00 \pm 14.08$ & $0.63 \pm 0.12$ & $4.02 \pm 1.34$ & $4.63 \pm 1.36$ \\
\hline & $P$ & 0.012 & 0.001 & 0.024 & 0.013 & 0.017 & 0.147 & 0.092 & 0.075 & 0.316 \\
\hline
\end{tabular}

Abbreviations: Apo AI: apolipoprotein AI; Apo B: apolipoprotein B; CRE: creatinine; CRP: C-reactive protein; HDL-chol: high density lipoprotein cholesterol; LDL-chol: low density lipoprotein cholesterol; TC: total cholesterol; TG: triglycerides. Values are mean \pm SD.

TABLE 4: Kinetic of conjugated dienes formation from oxidized LDL of both study groups after 3 weeks of argan oil intervention.

\begin{tabular}{|c|c|c|c|c|}
\hline \multirow{2}{*}{ Groups } & & \multicolumn{3}{|c|}{ Markers of susceptibility of LDL to lipid peroxidation } \\
\hline & & $\mathrm{LP}(\mathrm{min})$ & $\mathrm{MR}$ (mol diene/mol LDL/min) & MDP (mol diene/mol LDL) \\
\hline \multirow{3}{*}{ Control } & After stabilization (2 weeks) & 53.45 & 3.83 & 520.17 \\
\hline & After intervention ( 3 weeks) & 52.70 & 3.86 & 521.80 \\
\hline & $P$ & 0.189 & 0.207 & 0.180 \\
\hline \multirow{3}{*}{ Argan oil } & After stabilization (2 weeks) & 52.00 & 3.88 & 522.70 \\
\hline & After intervention ( 3 weeks) & 63.10 & 1.04 & 338.60 \\
\hline & $P$ & 0.027 & 0.031 & 0.019 \\
\hline
\end{tabular}

Abbreviations: LP: lag phase; MDP: maximum dienes production; MR: maximal rate of dienes production. Values are means \pm SD.

$[22,23]$. Another study showed that intake of argan oil, improves insulin signaling in fat and liver beyond levels found in a rat model of dietary-induced obesity [43].

The lipid lowering effect of argan oil was investigated for the first time in diabetic patients, in this study and it could be expected because of the interesting level of unsaturated fats and the ratio of PUFA/SFA (3.34) and of MUFA/PUFA (1.63) [20]. PUFA has protective effects against oxidation, as explained by the presence of the double bonds. Argan oil is rich in oleic and linoleic acids that show less susceptibility to peroxidation [20]. Moreover, linoleic acid derivatives, particularly gamma-linolenic acid are shown potent in reducing blood cholesterol in humans and rats [44-46].

Also, argan oil is rich in phytosterols known for their beneficial effects on lipid markers [47-51]. The hypocholesterolemic effect of argan oil may be due to its high content in sterols in the minor compounds fraction. A recent study shows that plant sterols in patients with hypercholesterolemia reduce the concentration of cholesterol in both LDL and small LDL which are considered the more atherogenic particles [52, 53].

It is well documented that Apo AI is inversely correlated to CVD risk as to HDL-chol level. Apo AI as HDL-chol levels have significantly increased after argan oil intervention assuming that argan oil is antiatherogenic oil and could be used as nutritional preventive oil.
The diabetic patients in this study present a tendency to decrease the Apo B/Apo AI ratio after argan oil intervention, while they have showed an elevated Apo B/Apo AI ratio at baseline as in patients with metabolic syndrome, coronary artery disease, and with ischemic stroke $[54,55]$.

The interesting finding of this study was the combination of the decrease of triglycerides and Apo B/Apo AI ratio and the increase of HDL-chol, obtained after argan oil consumption which could reduce the percentage of metabolic syndrome observed among the patients, thus giving a beneficial role in the management of metabolic complications associated with metabolic syndrome in type 2 diabetics.

At the end of intervention period, we observed an important and significant increase of lag phase of conjugated dienes formation in LDL oxidation. This may be explained by the fact that isolated LDL particles from patients might be enriched with different antioxidants from argan oil diets, reducing their susceptibility to lipid peroxidation $[56,57]$. Drissi et al. [22] showed that sterol, tocopherol, and phenol compounds from argan oil increase the resistance of LDL to oxidation in healthy subjects. This study brings a new demonstration of the antioxidant effect of argan oil.

The trend of reduction of CRP is important considering the improve of insulin sensitivity in target tissue and may increase the ability of insulin to induce its beneficial effect on lipid metabolism. 


\section{Conclusion}

Our findings show for the first time that consumption of argan oil may have an antiatherogenic effect by improving lipids and apolipoprotein AI and the susceptibility of LDL to oxidation in type 2 diabetes patients with dyslipidemia and can therefore be recommended in the nutritional management of type 2 diabetes.

\section{Conflict of Interests}

All the authors declare that there are no conflict of interests.

\section{Acknowledgments}

The authors gratefully would like to thank Zakaria Ouissafane, the Argan oil Company Director, for his contribution of argan oil needed in the study. Also, their thanks are given to Agrotech Association SMD for their financial support and to Dr A. Belhouari for his statistical analysis. Great thanks are given to the nursing staff of Endocrinology and Nutrition and Metabolic Diseases Department, the University Hospital of Ibn Sina, Rabat, Morocco.

\section{References}

[1] A. G. Athyros, K. Tziomalos, A. Karagiannis, and D. P. Mikhailidis, "Dyslipidaemia of obesity, metabolic syndrome and type 2 diabetes mellitus: the case for residual risk reduction after statin treatment," Open Cardiovascular Medicine Journal, vol. 5, pp. 24-34, 2011.

[2] M. A. Tazi, S. Abir-Khalil, N. Chaouki et al., "Prevalence of the main cardiovascularriskfactors in Morocco: results of a national surveyin 2000," Journal of Hypertension, vol. 21, pp. 897-903, 2003.

[3] L. Zhang, Q. Qiao, J. Tuomilehto et al., "Blood lipid levels in relation to glucose status in sevenpopulations of Asian origin without a prior history of diabetes: the DECODA study," Diabetes/Metabolism Research and Reviews, vol. 25, no. 6, pp. 549557, 2009.

[4] B Vergès, "Combination lipid therapy in type 2 diabetes mellitus," Expert Opin Pharmacother, vol. 9, pp. 1393-1403, 2011.

[5] B. Verggès, "New insight into the pathophysiology of lipid abnormalities in type 2 diabetes," Diabetes and Metabolism, vol. 31, no. 5, pp. 429-439, 2005.

[6] D. D. Thomas, "Understanding hypertriglyceridemia in women: clinical impact and management with prescription omega-3-acid ethyl esters," International Journal of Women's Health, vol. 3, pp. 87-97, 2011.

[7] A. D. Sniderman, "Non-HDL cholesterol versus apolipoprotein $\mathrm{B}$ in diabetic dyslipoproteinemia: alternatives and surrogates versus the real thing," Diabetes Care, vol. 26, no. 7, pp. 2207-2208, 2003.

[8] N. Sathavarodom and A. Boonyavarakul, "Apolipoprotein $B$ level in patients with type 2 diabetes who achieved goal of low density lipoprotein cholesterol and non-high density lipoprotein cholesterol," Journal of The Medical Association of Thailand, vol. 93, pp. 166-172, 2010.

[9] J. D. Brunzell, M. Davidson, C. D. Furberg et al., "Lipoprotein management in patients with cardiometabolic risk: consensus statement from the American diabetes association and the american college of cardiology foundation," Journal of the American College of Cardiology, vol. 51, pp. 1512-1524, 2008.

[10] D. E. Barre, K. A. Mizier-Barre, O. Griscti, and K. Hafez, "No gender associated differences in LDL oxidation in response to a CuSO4 challenge in a population of Caucasians with well-controlled type 2 diabetes," International Journal of Diabetes and Metabolism, vol. 17, no. 3, pp. 81-85, 2009.

[11] K. Kulkarni, H. Tiwari, L. Moore, and S. Jones, "A novel approach to measure apolipoprotein B/apolipoproteinAI ratio using the vertical auto profile method," Diabetes and Vascular Disease Research, vol. 4, p. 266, 2007.

[12] R. Frenais, K. Ouguerram, C. Maugeais et al., "High density lipoprotein apolipoprotein AI kinetics in NIDDM: a stable isotope study," Diabetologia, vol. 40, no. 5, pp. 578-583, 1997.

[13] G. Walldius and I. Jungner, "The apo B/apo AI ratio: a strong, new risk factor for cardiovascular disease and a target for lipid-lowering therapy: a review of the evidence," Journal of Internal Medicine, vol. 259, no. 5, pp. 493-519, 2006.

[14] G. Walldus, I. Jungner, A. H. Aastveit, I. Holme, C. D. Furberg, and A. D. Sniderman, "The apo B/apo AI ratio is better than the cholesterol ratios to estimate the balance between plasma proatherogenic and antiatherogenic lipoproteins and to predict coronary risk," Clinical Chemistry and Laboratory Medicine, vol. 42, no. 12, pp. 1355-1363, 2004.

[15] T. Nyström, "C-reactive protein: a marker or a player?" Clinical Science, vol. 113, no. 1-2, pp. 79-81, 2007.

[16] B. Lu, Y. Yang, Z. Yang et al., "Insulin resistance in Chinese patients with type 2 diabetes is associated with C-reactive protein independent of abdominal obesity," Cardiovascular Diabetology, vol. 9, p. 92, 2010.

[17] R. M. Krauss, "Lipids and lipoproteins in patients with type 2 diabetes," Diabetes Care, vol. 27, no. 6, pp. 1496-1504, 2004.

[18] F. Khallouki, C. Younos, R. Soulimani et al., "Consumption of argan oil (Morocco) with its unique profile of fatty acids tocopherols, squalene, sterols, and phenolic compounds should confer valuable cancer chemo-preventive effects," European Journal of Cancer Prevention, vol. 12, no. 1, pp. 67-75, 2003.

[19] Y. Berrada, A. Settaf, K. Baddouri, A. Cherrah, and M. Hassar, "Experimental assessment of antihypertensive and hypolipidemic effects of oil of Argan, Argania sideroxylon," Therapie, vol. 55, no. 3, pp. 375-378, 2000.

[20] H. Berrougui, A. Ettaib, M. D. Herrera Gonzalez, M. Alvarez De Sotomayor, N. Bennani-Kabchi, and M. Hmamouchi, "Hypolipidemic and hypocholesterolemic effect of Argan oil in Merionesshawi rats," Journal of Ethnopharmacology, vol. 89, no. 1, pp. 15-18, 2003.

[21] H. Berrougui, M. Alvarez de Sotomayor, C. Pérez-Guerrero et al., "Argan (arganiaspinosa) oil lowers blood pressure and impreves endothelial dysfunction in spontaneously hypertensive rats," The British Journal of Nutrition, vol. 92, no. 6, pp. 921-929, 2004.

[22] A. Drissi, J. Girona, M. Cherki et al., "Evidence of hypolipemiant and antioxydant properties of argan oil derived from the argan tree (arganiaspinosa)," Clinical Nutrition, vol. 23, pp. 1159-1166, 2004.

[23] A. Derouiche, M. Cherki, A. Drissi et al., "Nutritional intervention study with argan oil in man: effects on lipids and apolipoproteins," Annals of Nutrition and Metabolism, vol. 49, no. 3, pp. 196-201, 2005.

[24] Z. Charrouf and D. Guillaume, "Argan oil: occurrence, composition and impact on human health," European Journal of Lipid Science and Technology, vol. 110, no. 7, pp. 632-636, 2008. 
[25] H. E. Monfalouti, D. Guillaume, C. Denhez, and Z. Charrouf, "Therapeutic potential of argan oil: a review," Journal of Pharmacy and Pharmacology, vol. 62, no. 12, pp. 1669-1675, 2010.

[26] M. Boukhobza and N. Pichon-Prun, "L'arganier ressource economiqueetmedicinale pour le Maroc," Phytotherapie, vol. 27, pp. 21-26, 1988.

[27] W. Richmond, "Preparation and properties of a cholesterol oxidase from Nocardia sp. and its application to the enzymatic assay of total cholesterol in serum," Clinical Chemistry, vol. 19, no. 12, pp. 1350-1356, 1973.

[28] P. Trinder, "Enzymatic method of triglycerides," Annals of Clinical Biochemistry, vol. 6, pp. 24-27, 1969.

[29] W. T. Friedewald, R. I. Levy, and D. S. Fredrickson, "Estimation of the concentration of low-density lipoprotein cholesterol in plasma, without use of the preparative ultracentrifuge," Clinical Chemistry, vol. 18, no. 6, pp. 499-502, 1972.

[30] W. Becker, W. Rapp, H. G. Schenk, and K. Störiko, "Methodenzur quantitative Bestimmung von Plasma protein endurchImmunpräzipitation," Zeitschrift für Klinische Chemie und Klinische Biochemie, vol. 6, pp. 113-122, 1968.

[31] J. Siedel, S. Schiefer, M. Rosseneu et al., "Method for routine determinations of apolipoproteins AI, AII and B in normoand hyperlipemic sera compared with immunonephelometry," Clinical Chemistry, vol. 34, no. 9, pp. 1821-1825, 1988.

[32] N. Rifai and M. E. King, "Immunoturbidimetric assays of apolipoproteins A, AI, AII, and B in serum," Clinical Chemistry, vol. 32, no. 6, pp. 957-961, 1986.

[33] H. K. Naito, "Reliability of lipid, lipoprotein, and apolipoprotein measurements," Clinical Chemistry, vol. 34, no. 8, pp. 84-94, 1988.

[34] O. Senju, Y. Takagi, K. Gomi, N. Ishii, S. Mochizuki, and N. Ishii, "The quantitative determination of CRP by latex agglutination photometric assay," Japanese Journal of Clinical Laboratory Automation, vol. 8, pp. 161-165, 1983.

[35] C. P. Price, A. K. Trull, D. Berry, and E. G. Gorman, "Development and validation of a particle-enhanced turbidimetric immunoassay for C-reactive protein," Journal of Immunological Methods, vol. 99, no. 2, pp. 205-211, 1987.

[36] S. Eda, J. Kaufmann, W. Roos, and S. Pohl, "Development of a new microparticle-enhanced turbidimetric assay for Creactive protein with superior features in analytical sensitivity and dynamic range," Journal of Clinical Laboratory Analysis, vol. 12, no. 3, pp. 137-144, 1998 .

[37] M. Jaffé, "Ueber den Niederschlag, welchen Pikrinsäure in normalem Harnerzeugt und übereineneue Reaction des Kreatinins," Zeitschrift für Physikalische Chemie, vol. 10, pp. 391-400, 1886.

[38] D. L. Fabiny and G. Ertingshausen, "Automated reaction-rate method for determination of serum creatinine with the CentrifiChem," Clinical Chemistry, vol. 17, no. 8, pp. 696-700, 1971.

[39] H. Bartels and M. Böhmer, "Micro-determination of creatinine," Clinica Chimica Acta, vol. 32, pp. 81-85, 1971.

[40] W. Sattler, D. Mohr, and R. Stocker, "Rapid isolation of lipoproteins and assessment of their peroxidation by high-performance liquid chromatography postcolumn chemiluminescence," Methods in Enzymology, vol. 233, pp. 469-489, 1994.

[41] H. A. Kleinveld, H. L. M. Hak-Lemmers, A. F. H. Stalenhoef, and P. N. M. Demacker, "Improved measurement of low density lipoprotein Susceptibility to copper-induced oxidation: application of a Short procedure for isolating low density lipoprotein," Clinical Chemistry, vol. 38, no. 10, pp. 2066-2072, 1992.

[42] K. G. Alberti, P. Zimmet, and J. Shaw, "Metabolic syndrome," Diabetic Medicine, vol. 23, no. 5, pp. 469-480, 2006.

[43] S. Samane, R. Christon, L. Dombrowski et al., "Fish oil and argan oil intak differently modulate insulin resistance and glucose intolerance in a rat model of dietary induced obesity," Metabolism, vol. 58, no. 7, pp. 909-919, 2009.

[44] A. Keys, J. Anderson, and F. Grande, "Prediction of serum cholesterol response of man to change in fats in the diet," The Lancet, vol. 270, no. 7003, pp. 959-966, 1957.

[45] D. M. Hegsted, R. B. McGandy, M. L. Myers, and F. J. Stare, "Quantitative effects of dietary fat on serum cholesterol in man," The American Journal of Clinical Nutrition, vol. 17, no. 5, pp. 281-295, 1965.

[46] R. Takada, M. Saitoh, T. Mori et al., "Dietary gamma-linolenic acid enriched oil reduces body fat content and induces liver enzyme activities relating to fatty acid beta-oxidation in rats," Journal of Nutrition, vol. 124, pp. 469-474, 1994.

[47] A. Nagyova, P. Haban, J. Klvanova, and J. Kadrabova, "Effects of dietary extra virgin olive oil on serum lipid resistance to oxidation and fatty acid composition in elderly lipidemic patients," Bratislavske Lekarske Listy, vol. 104, no. 7-8, pp. 218-221, 2003.

[48] T. Heinemann, G. Axtmann, and K. Von Bergmann, "Comparison of intestinal absorption of cholesterol with different plant sterol in man," European Journal of Clinical Investigation, vol. 23, no. 12, pp. 827-831, 1993.

[49] S. Khandelwal, I. Demonty, P. Jeemon et al., "Independent and interactive effects of plant sterols and fisch oil n-3 long-chain polyunsaturated fatty acids on the plasma lipid profile of mildly hyperlipideamic Indian adult," The British Journal of Nutrition, vol. 102, no. 5, pp. 722-732, 2009.

[50] I. Demonty, R. T. Ras, H. C. M. van Der Knaap et al., "Continuous dose-response relationship of the LDL-cholesterol-lowering effect of phytosterol intake," Journal of Nutrition, vol. 139, no. 2, pp. 271-284, 2009.

[51] F. Marangoni and A. Poli, "Phytosterols and cardiovascular health," Pharmacological Research, vol. 61, no. 3, pp. 193-199, 2010.

[52] K. A. Varady, A. C. St Pierre, B. Lamarche, and P. J. H. Jones, "Effect of plant sterols and endurance training on LDL particle size and distribution in previously sedentary hypercholesterolemic adults," European Journal of Clinical Nutrition, vol. 59, no. 4, pp. 518-525, 2005.

[53] J. M. Malinowski and M. M. Gehret, "Phytosterols for dyslipidemia," American Journal of Health-System Pharmacy, vol. 67, no. 14, pp. 1165-1173, 2010.

[54] L. M. Lima, M. D. G. Carvalho, A. D. P. Sabino, A. P. L. Mota, A. P. Fernandes, and M. O. Sousa, "Apo B/apo A-I ratio in central and peripheral arterial diseases," Arquivos Brasileiros de Endocrinologia e Metabologia, vol. 51, no. 7, pp. 1160-1165, 2007.

[55] J. Sierra-Johnson, V. K. Somers, F. H. S. Kuniyoshi et al., "Comparison of apolipoprotein-B/apolipoprotein-AI in subjects with versus without the metabolic syndrome," The American Journal of Cardiology, vol. 98, no. 10, pp. 1369-1373, 2006.

[56] B. Fuhrman, A. Lavy, and M. Aviram, "Consumption of red wine with meals reduces the susceptibility of human 
plasma and low-density lipoprotein to lipid peroxidation," The American Journal of Clinical Nutrition, vol. 61, no. 3, pp. 549-554, 1995.

[57] I. Jialal, C. J. Fuller, and B. A. Huet, "The effect of $\alpha$-tocopherol supplementation on LDL oxidation. A dose-response study," Arteriosclerosis, Thrombosis, and Vascular Biology, vol. 15, no. 2, pp. 190-198, 1995. 


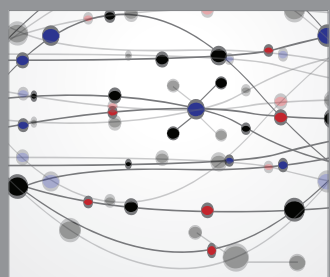

The Scientific World Journal
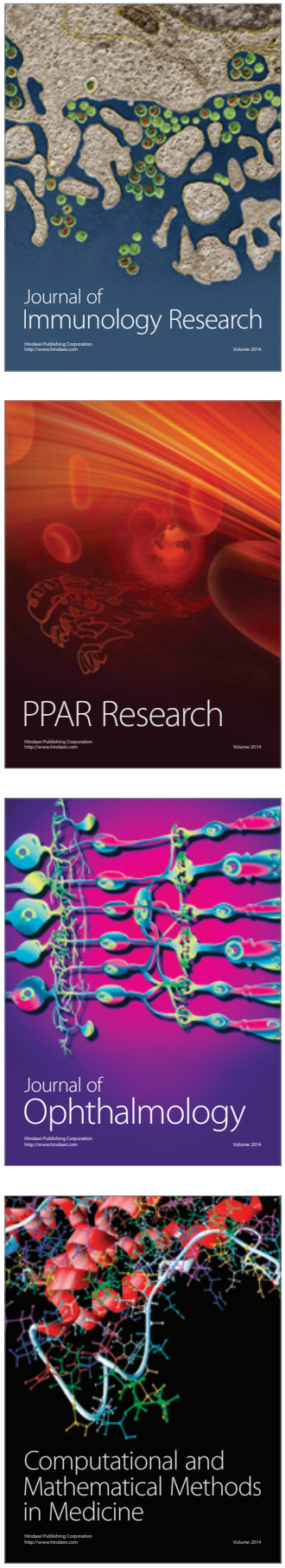

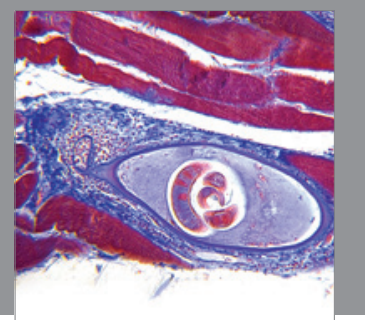

Gastroenterology

Research and Practice
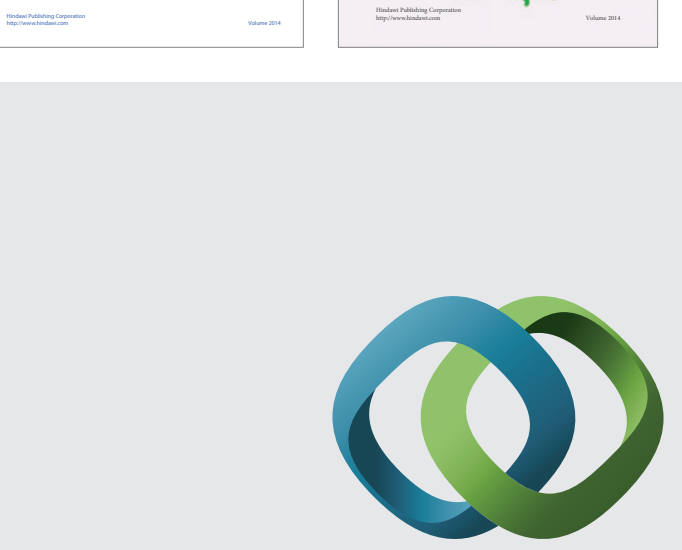

\section{Hindawi}

Submit your manuscripts at

http://www.hindawi.com
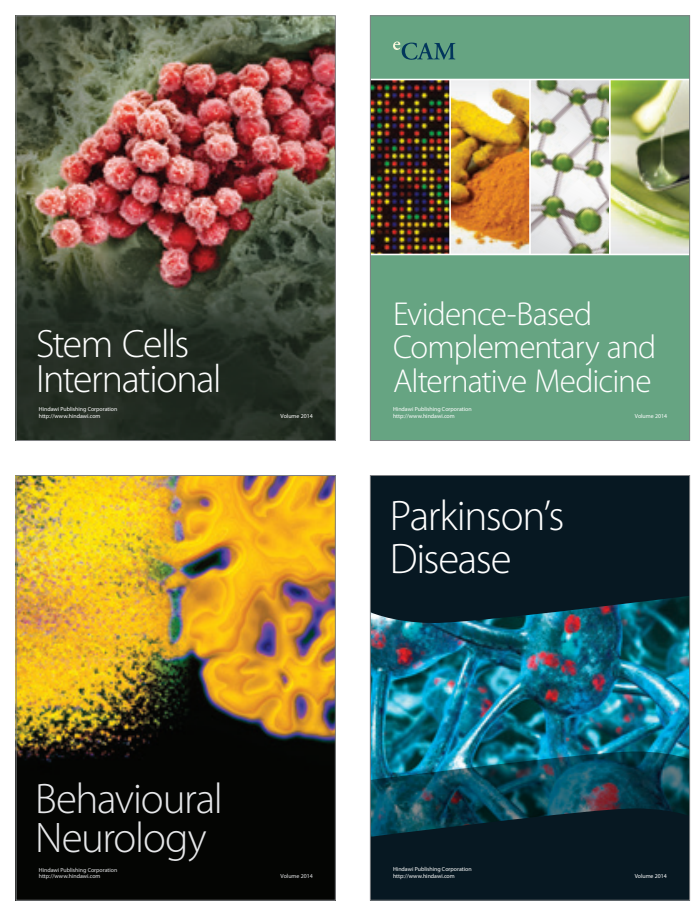

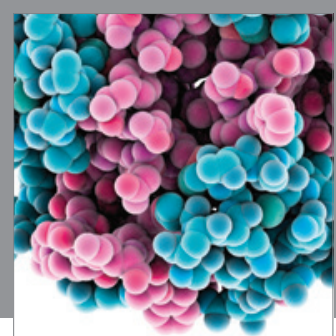

Journal of
Diabetes Research

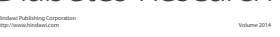

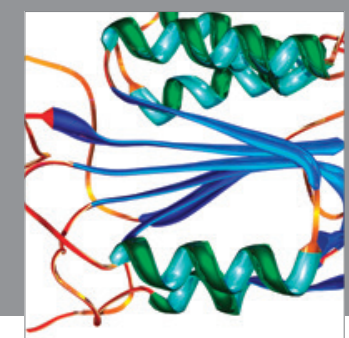

Disease Markers
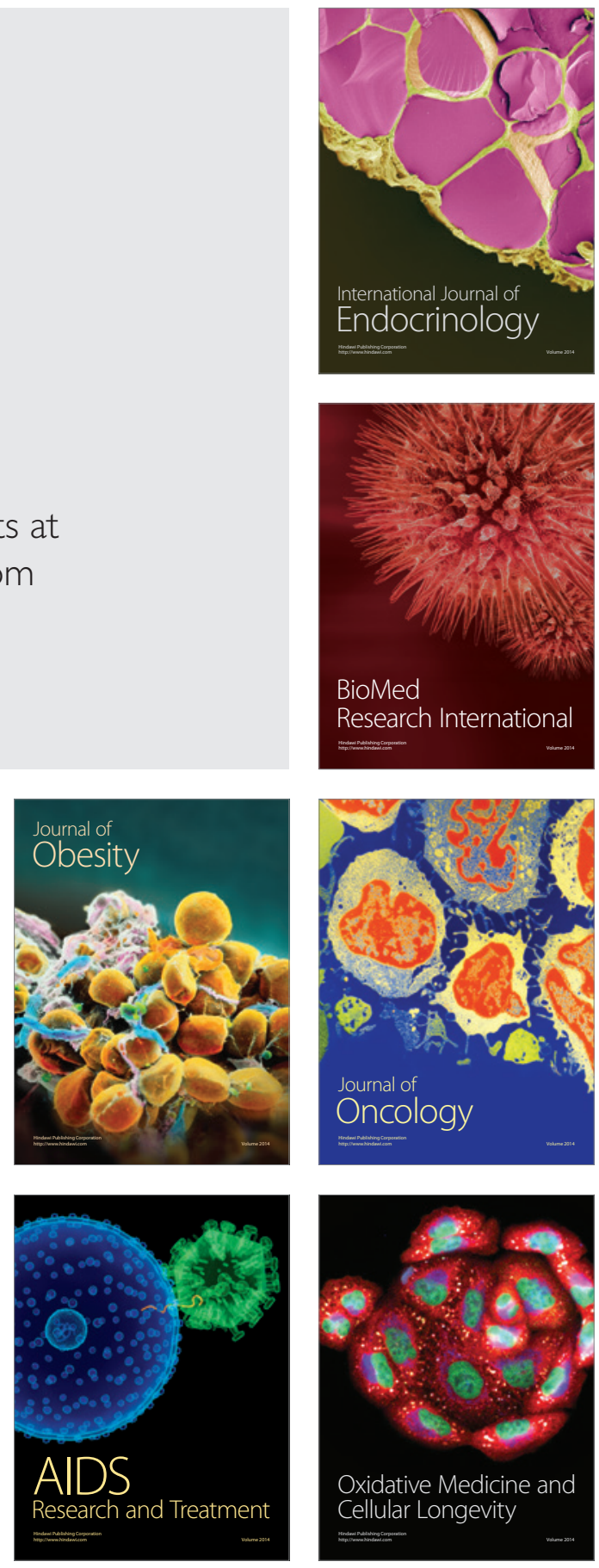